Volume: 1 | Volumen 1 | Número 1 | Number 1 | pp. 109 - 119 ISSN: 2634-355X (Print) | ISSN: 2634-3568 (Online) journals.tplondon.com/yeiya

First Submitted: 11 September 2020 Accepted: 28 November 2020

DOI: https://doi.org/10.33182/y.v1i1.1261

\title{
La pandemia COVID-19: desafío al discurso de desarrollo bajo el modelo económico neoliberal
}

\author{
A. Fabiola Urquizú Solís ${ }^{1}$
}

\section{Resumen}

El modelo capitalista neoliberal que rige el mundo en el siglo XXI, no puede negar la alarmante situación de muertes por COVID-19, así como tampoco su incapacidad para responder ante el impacto económico que está generando dicha pandemia. No tener el control hasta estos momentos de lo primero pone fuera de sus manos el control de lo segundo. La dinámica de libre mercado queda restringida ante epidemias mundiales o crisis ambientales de alto nivel. El desarrollo pensado desde "arriba" no alcanza a explicar las consecuencias que el fenómeno de crisis sanitaria mundial está ocasionando a nivel económico, social y politico. El post-desarrollo empieza a tener sentido, al cuestionar el concepto de crecimiento económico y sus metas, pugnando por incluir una cosmovisión como fundamento de un nuevo modelo de desarrollo a nivel mundial. Este trabajo tiene como propósito evidenciar la necesidad de incluir nuevas formas de desarrollo que contemplen múltiples universos.

Palabras clave: desarrollo; post-desarrollo; COVID-19; libre mercado; cosmovisión

\begin{abstract}
The COVID-19 pandemic: challenge to the development discourse under the neoliberal economic model

The neoliberal capitalist model that rules the world in the 21st century cannot deny the alarming situation of deaths from COVID-19, as well as its inability to respond to the economic impact that this pandemic is generating. Not being in control of the former until now puts control of the latter out of their hands. Free market dynamics are restricted by global epidemics or high-level environmental crises. The development thought from "above" fails to explain the consequences that the global health crisis phenomenon is causing at the economic, social and political level. For this reason, post-development begins to make sense, by questioning the concept of economic growth and its goals, striving to include a worldview as the foundation of a new development model worldwide. The purpose of this work is to demonstrate the need to include new forms of development that contemplate multiple universes.
\end{abstract}

Keywords: development, post-development, COVID-19, free market, worldview

\section{Introducción}

La situación que se vive en estos momentos a nivel mundial ante la pandemia COVID-19 es de incertidumbre y asombro, la ficción alcanzó a la realidad. Cabe recordar como en pocas semanas la propagación del virus que surgió en la ciudad de Wuhan al este de China, se propagó por el planeta. El rápido contagio, la capacidad de transmisión, la gravedad clínica y el periodo de infección, hace de este virus un acontecimiento sea difícil de controlar y predecir,

\footnotetext{
${ }^{1}$ Universidad Autónoma de Sinaloa. Culiacán, México. Correo electrónico: fabiola.urquizu9@gmail.com
} 
las primeras medidas extremas que se tuvieron que tomar fueron el distanciamiento social, cierre de fronteras, suspensión de actividades económicas, lo que generó desequilibrios en el mercado financiero mundial. Tal escenario, ha evidenciado en cada nación condiciones internas de necesidades sociales no cubiertas, que van desde el sistema de salud, hasta políticas de seguridad social para responder a la amenaza sanitaria.

Esta contingencia se da en un momento en que la efectividad del sistema económico mundial que predomina es cuestionada (Fox, 2001; Harvey, 2006; Sassen, 2016; Chomsky y Polychroniou, 2017). Los indicadores de desigualdad, de pobreza, de alta contaminación, de injusticia e inequidad han generado críticas y descontento al proyecto neoliberal que rige actualmente. El desarrollo que prometía el libre mercado no se vio cristalizado (Villamizar y Uribe, 2009). Surgen otras propuestas que proponen un desarrollo alternativo que contemple la cosmovisión de un mundo pluricultural, protegiendo la madre naturaleza (Gudynas, 2014).

El texto parte de explicar que es el desarrollo en una visión del modelo capitalista neoliberal de dónde surge, y en qué contexto de la historia se hace presente, así también explica cómo es que se instaura en países no desarrollados. En otro apartado se mencionan ciertas causas del porqué el modelo de libre mercado fracasó en algunas naciones y evidencia que las premisas no fueron cumplidas. Es en la lucha por seguir posicionando este modelo económico que surge la pandemia del COVID-19, la cual se describe en otro apartado considerando sus dimensiones hasta el día de hoy en un contexto de globalización. Por último, se presentan nuevas visiones de entender desarrollo, diferente a la concepción colonialista del capitalismo.

La intención es que a partir de la urgencia sanitaria mundial se evidencie que el sistema económico imperialista no debería reinar como doctrina normativa en el mundo, es conveniente reconocer que existen formas de ser, hacer y saber que pueden desarrollarse plenamente desde su cosmovisión.

\section{E1 desarrollo y el modelo capitalista neoliberal}

Es en 1947 cuando surge la dicotomía desarrollo-subdesarrollo, bajo un escenario de guerra "la génesis se puede ubicar a mediados del siglo pasado, en el marco de la reconstrucción europea de posguerra y la conformación del sistema internacional de Bretton Woods" (Nahón, Rodríguez, y Schorr, 2006: 328). Había terminado la Segunda Guerra Mundial, con un desorden lleno de devastación, hambruna, pobreza, y desanimo social; los países vencidos requerían de un sustento económico y político que los ayudara a salir de tal crisis. La intervención del Estado se volvió importante y figuró como agente necesario para el rescate; fueron los países aliados quienes se harían cargo, definiéndose entonces el nuevo orden mundial al evidenciar cuales eran los países dominantes de esa época. Junto a todo esto la ideología política y económica también se volvió relevante, se convirtieron en Estados transformadores, que daban recetas y asesoramiento internacional a los países devastados.

En esa misma década pensadores del desarrollo como Rosestein-Rodan (1943), Nurkse (1952), y Rostow (1960) proponían para las regiones subdesarrolladas la intervención pública en la promoción y coordinación de la inversión en la economía; considerando el desarrollo como un proceso. Mientras que Myrdal (1957) y Hirschman (1958) apostaban a una visión más armónica con una mayor intervención estatal para proteger los mercados, con características como la protección a la pequeña industria y la promoción de encadenamientos productivos, entre otras (Nahón et al., 2006). Ya Myrdal (1957) anunciaba que los mecanismos 
del mercado lejos de mostrar una tendencia a eliminar las diferencias entre regiones, las acentuaban:

Si en una determinada región hay ausencia de efectos impulsores, la demanda de capital permanece a niveles relativamente bajos limitando las posibilidades de crecimiento y por lo tanto se favorece la transferencia de recursos hacia regiones desarrolladas (Diez, Gutiérrez y Pazzi, 2013: 205).

Estados Unidos de América (EUA) y algunos países europeos tuvieron un importante crecimiento en sus economías llevando la delantera a nivel global, periodo al que se le denominó 'años dorados' (1945-1973). El Plan Marshall que pasaría a la historia como el proyecto de reconstrucción civil más exitoso por EUA en el siglo XX, sirvió de antesala para que se diera el desarrollo de los países europeos. Las intenciones conocidas por todos eran, la recuperación en infraestructura de los países golpeados por la guerra, contrarrestar el hambre, la pobreza, la desesperación y el caos. Más allá de eso, se buscaba recobrar la salud económica mundial, porque de otra manera no llegaría la estabilidad y la paz. Sin embargo, la intención oculta siempre fue, detener el comunismo de la Unión Soviética en el este de Europa.

En el caso de EUA a finales de la década de 1960 y principios de los 70 con la Crisis del petróleo de 1973 se derrumba el modelo económico de Estado de Bienestar, que fuera un sistema económico que mantuviera fuerte a la potencia estadounidense y a algunos países europeos en crecimiento. El keynesianismo se caracterizó por promover un Estado muy activo, que intervenía en la economía por medio de la política fiscal, garantizaba la ocupación (empleo) y el consumo. Además de la crisis petrolera, una serie de eventos como la reducción de la paridad del dólar frente al oro en 1971, los costos de la Guerra Fría y las pérdidas económicas que trajo consigo la Guerra de Vietnam, terminaron por hundir la política de Estado de Bienestar (Doxrud, 2017).

Este escenario fue el oportuno para las ideas de Milton Friedman, el monetarismo de la Escuela de Chicago comenzó a abrirse paso. Lo anterior implicaba un rol menos preponderante del Estado en la economía, dejando su regulación al libre mercado. Milton Friedman y George Stigler fueron dos de los mayores representantes del nuevo modelo económico neoliberal, que surgió en la escuela de negocios de la universidad de Chicago a mediados del siglo XX, este pensamiento se contraponía a las teorías keynesianas, inclinándose por un enfoque monetarista (Murray, 1999).

Las teorías de la entonces ya llamada Escuela de Chicago, congeniaban con muchas de las políticas del Banco Mundial (BM) y el Fondo Monetario Internacional (FMI), las cuales apoyaban el Conceso de Washington, otro paquete de políticas que tenía como objetivo recetar medidas para provocar el desarrollo mayoritariamente en países no desarrollados. Esta nueva corriente económica logró esparcirse por toda América, materializándose en el cambio de patrón productivo, al mudarse de un modelo de Industrialización por Sustitución de Importaciones (ISI) a otro de apertura económica (Bustelo, 1998). Sin profundizar a detalle sobre los diez puntos que expresaba el Consenso, se debe rescatar que ninguno de esos puntos que guiarían la política económica en los países subdesarrollados contemplaban las grandes desigualdades o la marcada pobreza existente. "La reforma tributaria, la privatización, la abolición de los subsidios y la reducción del gasto público requeridas para eliminar los déficit presupuéstales tenderían, indirectamente, a aumentar la inequidad" (Stewart, 1998: 37). 


\section{La pandemia COVID-19: desafío al discurso de desarrollo bajo el modelo económico neoliberal}

El desarrollo desde entonces se ha tomado como estandarte para implementar estrategias económicas que prometen bienestar social, viéndose reflejadas en la estructura dominante de las sociedades, impactando en la forma de producción, discursos y pensamientos. El discurso del promotor del libre mercado (Friedman, 1966) aseguraba que el mercado garantizaría al individuo la libertad de aprovechar al máximo todos los recursos que estuvieran a su disposición siempre y cuando no interfirieran con la libertad de los demás de hacer lo mismo. No obstante, eso no garantizaría que tendrán los mismos recursos que otros, sin que se pudiera haber evitado la existencia de una gran disparidad entre riquezas e ingresos.

El reacomodo económico mundial hegemónico que predominaba en los países en desarrollo dejó de lado las cuestiones sociales: al contrario, sus bases descansaban en los mecanismos del mercado y una concepción individual. La lógica del capital financiero globalizado ha sido la búsqueda de ganancias extraordinarias; esto confiere al capital la característica de volatilidad, dando la libertad de retirar las ganancias de cierto mercado que ya no resulte favorable, y con esto, precipitando una crisis financiera (Calvento, 2007).

El neoliberalismo surge con el propósito de restaurar el liberalismo amenazado por las tendencias colectivistas del siglo XX, el programa neoliberal necesita al Estado para que este sirva como instrumento en el proceso de privatización (Escalante, 2015). El término neoliberal fue sugerido por el sociólogo y economista alemán Alexander Rüstow, quien reconoció que la economía de laissez-faire ya no era suficiente; por consiguiente, el liberalismo debía ser estructurado con una política económica moderna (Stedman, 2012). A palabras de David Harvey (2007), "los fundadores del pensamiento neoliberal tomaron el ideal político de la dignidad y de la libertad individual como pilar fundamental, considerando los valores centrales de la civilización” (p. 11).

La consolidación del pensamiento neoliberal como un nuevo modelo económico regulador de la política pública a nivel estatal en el mundo del capitalismo avanzado se dio en EUA con Ronald Reagan y en Gran Bretaña bajo el mandato de Margaret Thatcher en 1979 (Harvey, 2007), aunque anteriormente ya había sido probado en Chile en 1973 con el golpe de estado al gobierno de Salvador Allende orquestado por Augusto Pinochet.

Andrés Villena (2016) señala que el orden neoliberal favorece de manera desproporcional solamente a unos pocos, los números reales difieren la idea de que el beneficio es para todos. Algunas afirmaciones fundamentales que hace el neoliberalismo parecieran ser indiscutibles: (i) una empresa privada es siempre más eficiente que una empresa pública; (ii) la competencia produce siempre los mejores resultados; o (iii) los hombres tienen la necesidad de buscar siempre la máxima ventaja personal. Esas nociones ya aceptadas por el sentido común de la población mantienen vigente la corriente neoliberal. La neoliberalización es un proceso creciente de mercantilización de derechos.

El modelo neoliberal de libre mercado, ofrece ventajas en la importación y exportación de mercancía, permitiendo a las naciones beneficiarse de acuerdos comerciales, con la promesa de poder ofrecer productos competitivos al mercado interno. Al mismo tiempo, permite la inversión Extranjera Directa (IED) que asegura la generación de más empleo, y representa una apertura en el comercio mundial para las naciones. Además de que el Estado deja de ser protector de la industria nacional para volverse el promotor de la inversión privada. La apertura representa mejoramiento en la infraestructura, entre otras características. 
Lo anterior parece muy atractivo, la promesa de adoptar las medidas neoliberales permitió pensar a las naciones que podían alcanzar el desarrollo del primer mundo. Hasta estos momentos una parte de la sociedad cree firmemente en la efectividad de dicho modelo económico, guardan la esperanza de un ascenso social y el alcance del máximo beneficio a través de esta doctrina globalizadora. Lamentablemente, estas medidas trajeron consecuencias.

\section{El deterioro del modelo de desarrollo económico neoliberal}

La receta neoliberal parecía que era buena, o tal vez faltó aclarar, que lo era para unos cuantos. El discurso mundial es que la pobreza se acentúa y que las próximas generaciones tendrán un menor estándar de vida que el actual, ¿cómo puede estar pasando esto si el mundo tiene más riqueza en estos momentos? (ONU, 2018). La inequidad de los ingresos se ha profundizado, con ello el neoliberalismo no ha sido capaz de eliminar el Estado de Bienestar, se tiene un aumento en los gastos sociales debido al desempleo y al ascenso en el número de jubilados (Anderson, 1999). Así pues, el proyecto neoliberal consintió la recuperación de la clase burguesa, atacó a los sindicatos y apoyó a la Industria Privada por parte del Estado (Cajal, 2020).

Para 1991, el capitalismo entró en una profunda recesión, evidenciando el endeudamiento público de muchos países occidentales, además del endeudamiento de familias y empresas; por lo que se empezaba a cuestionar la eficacia del modelo neoliberal (Anderson, 1999). En el tema del comercio internacional no se lleva a cabo con libertad, por el contrario, el ordenamiento comercial mundial está en manos de las naciones más fuertes. El libre comercio ha lastimado actividades productivas tradicionales principalmente en naciones latinoamericanas, como lo es la agricultura, que deja a la industria en desventaja ante la producción con técnicas modernas de otras naciones. El error fue el abrir totalmente sus mercados a la competencia internacional, sin que esto fuera de manera gradual para lograr fortalecer la industria domestica (Anderson, 1999; Rubio, 2003).

Además del desempleo y el descuido de la industria agrícola por la competencia en desventaja en los países no desarrollados, no se ha logrado una estrategia consistente de desarrollo. El objetivo ha sido la estabilidad y la macroeconomía, menoscabando la sostenibilidad económica y la importancia de los derechos fundamentales; pero contrariamente la distribución del ingreso empeoró, hubo un aumento en el número de pobres, aumentaron los monopolios y la concentración del poder (González, 2003).

El índice deseable para las economías neoliberales se volvió la tasa de crecimiento, dejando en segundo lugar la política social, ya que el modelo de libre comercio asegura que entre mayor sea el crecimiento este implicaría mayor desarrollo y equidad social (Corredor, 2003). Sin embargo, se puede constatar para estos tiempos un rezago en la productividad, la región de Latinoamérica ha presentado una brecha cada vez más amplia con el resto del mundo (CEPAL, 2020); el desarrollo tecnológico (CCEPAL, 2016), se tiene mayor tasa de subempleos, entre los años 2018-2019 la tasa se incrementó 35\% (CEPAL, 2020); por lo tanto, esta situación golpea la equidad y el bienestar social.

En consecuencia, el reducir la participación del estado como lo indicaba el proyecto neoliberal, no funcionó en las economías subdesarrolladas. La privatización de las empresas, como ya se vio, redujo drásticamente el empleo público. Los gobiernos tuvieron que ajustar sus políticas 


\section{La pandemia COVID-19: desafío al discurso de desarrollo bajo el modelo económico neoliberal}

atendiendo exigencias internacionales y procesos globales, impidiendo efectuar políticas públicas acorde a la necesidad interna, situación que debilitó la agencia del Estado (Kay, 2009).

El resultado social que ha ocasionado la adopción del modelo neoliberal, se percibe en la desprotección de los individuos, sufren de inestabilidad laboral, falta de seguridad social, creciente pobreza que acarrea inseguridad, desigualdad, marginación, un sistema de educación privatizado que prioriza la acumulación de capital, la creación de nuevos impuestos, desmantelamiento de la propiedad pública, creciente contaminación ambiental, escasez de agua, cambio climático, pérdida de la biodiversidad, aculturación, y demás efectos que arrastra el capitalismo.

\section{La pandemia COVID-19}

Con el panorama descrito en el apartado anterior, en un contexto de globalización y competencia mundial regido por el beneficio económico a corto plazo, aparece la pandemia COVID-19. La libre competencia ha sido la justificación de conductas destructivas del hombre al entorno. Es posible, que la libertad de consumo, de producción, de uso de territorio, de explotación de la fuerza laboral, del uso del espacio público, y otros hechos, invadan la sana convivencia de los seres humanos y con ello se produzcan efectos amenazantes para la humanidad. ¡Qué más da!, tal escenario crea espacios de oportunidad para el capitalismo.

El nuevo brote de enfermedad por coronavirus COVID-19 fue notificado por primera vez el 31 de diciembre de 2019 en Wuhan, capital de la provincia de Hubei en el este de China; hasta el momento no se ha logrado confirmar su origen, pero según los datos disponibles sugieren que tiene un origen animal y no es un virus creado en un laboratorio; tampoco se precisa como se infectaron las primeras personas en China (OMS, 2020). Lo que sí es indiscutible es que la presencia de un virus de esa dimensión denota la vulnerabilidad humana económica, tecnológica, y científica, pero también logra que titubeé la dispersión del poder en el mundo.

Las dimensiones de la pandemia se siguen contabilizando, hasta este momento se pensaba que el punto álgido de la crisis había pasado. No obstante, actualmente se tiene 65 millones 870 mil 30 casos de contagio confirmados y se han registrado un millón 523 mil 583 muertes en el mundo (OMS, 2020). En la cuestión económica, el representante de la Organización Mundial del Comercio (OMC) Roberto Azevédo señaló que las proyecciones recientes predicen una recesión económica y una pérdida de empleos peores a lo visto en la crisis financiera mundial del 2008 (citado en Morales, 2020). Se calcula según la Organización Internacional del Trabajo (OIT) que se perderán aproximadamente 195 millones de empleos de tiempo completo, siendo el sector hotelero el más afectado (Orgaz, 2020).

El virus desconoce clase social, raza, o nacionalidad; y es la globalización su vehículo más eficaz. El libre mercado pregonó que el lucro estaba por encima de todo y de todos, desatendiendo la salud pública y los programas sociales. La elite del poder ha desestimado la vulnerabilidad en que viven cada vez más personas en espacios que no ofrecen bienestar, quienes tienen como principal preocupación el conseguir alimento dejando de lado cuestiones sanitarias.

El impulso económico deliberado de acumulación de capital y poder, que arrasa las cuestiones sociales y ambientales, y que es causado por el neoliberalismo no pudo evitar ni controlar los estragos que anunciaba la pandemia. La dimensión de la emergencia ha dejado sin validez el 
discurso de que la minoría es la culpable, por el contrario, es la prueba de que el neoliberalismo no ha logrado la inclusión de la humanidad, pero en estos momentos la situación ha obligado a la élite capitalista a voltear a ver al prójimo como su igual, como aquel que puede amenazar su propia estabilidad.

La crisis de salud mundial que representa este nuevo virus, deja claro que hace falta prevención con mayor apoyo a la salud pública y la ciencia; cuestiona cómo es que los Estados han destinado millonarias sumas de dinero a la compra de armamento, a actividades de ocio, la concesión de subsidios a grandes empresas, entre otros; esta situación ha dejado al descubierto una función pública al servicio de intereses económicos privados (Cueto, 2020).

El confinamiento que reclama la urgencia por detener la propagación mundial de la pandemia irrumpe el ritmo económico neoliberal, pero también hace evidente la disparidad de condiciones en que se deben resguardar las diferentes clases sociales; para una gran parte de la población se vuelve un problema por su situación de pobreza, aunado a otros como la flexibilidad laboral, escasez o mercantilización de los servicios básicos (Espinoza, 2020). Viene a bien retomar a David Harvey (2003), la "acumulación por desposesión" ha cobrado la estabilidad social, desprotegiendo a las mayorías; la situación actual confirma que el beneficio de las élites, en este caso, genera un malestar poblacional.

Otra característica de la dimensión del peligro por la infección del COVID-19 se aprecia en el ejercicio de los derechos y libertades civiles de las personas. No hay libertad de movimiento, se han implementado formas de control para asegurar la no ocupación del espacio público, medidas tan drásticas como la vigilancia por medio de helicópteros o drones para monitorear las zonas públicas; la supervisión de personas a través de aplicaciones móviles; o la que tomó el presidente de Filipinas meses atrás, al ordenar disparar a quién se encuentre en la calle si no respetan la cuarentena (El país, 2020).

Para quienes su único ingreso es el que resulta del trabajo diario, la emergencia que ordena el Estado de permanecer confinado les impide ejercer su libertad para alimentarse. Se han paralizado los servicios médicos públicos y privados para otros tipos de enfermedades. Se tiene una zozobra laboral por el riesgo de perder sus trabajos o quedar sin prestaciones mientras se está en encierro. ¿Habría entonces que re conceptualizar la libertad? ¿Cuáles serán las reales dimensiones del distanciamiento social posterior a la pandemia? ¿Es la amenaza de este nuevo virus la oportunidad de otorgar mayor poder al Estado y menor libertad al ciudadano?

\section{E1 post-desarrollo y la propuesta de un 'pluriverso'}

Un grupo de pensadores críticos del desarrollo como discurso occidental, han propuesto una visión más allá de un modelo eurocéntrico capitalista, comprendido a palabras de Orlando Fals Borda (1970) como un instrumento de colonialismo intelectual. La escuela postdesarrollista tiene su origen en la corriente del post-estructuralismo, liderado por el francés Michael Foucault (1968) con su crítica a la modernidad y sus mecanismos de poder.

Desde el surgimiento del concepto de desarrollo anteriormente explicado, se reconocen tres orientaciones teóricas contrastantes: la teoría de la modernización en los años 50, la teoría de la dependencia en los años 60 y 70, y las aproximaciones críticas del post-desarrollo a finales de los 80 y comienzo de los años 90 . Donde la primera sugería un proceso de desarrollo a replicar por los países pobres que incluía entre otras cosas la industrialización, la tecnificación 
agrícola, el mercado, y la racionalidad; la segunda por su parte, criticaba al capitalismo por su explotación de clase, y reconocía que había que superar la situación de dependencia de los países pobres hacia los países ricos; mientras que el post-desarrollo cuestiona al concepto mismo de desarrollo entendido como una invención de los países ricos (Escobar, 2013).

Esta última corriente del post-desarrollo, es reconocida por el intento de deconstruir el desarrollo, al considerar que es solo un discurso de poder y dominación; el principal argumento de esta crítica es que existen alternativas al desarrollo, pero también alternativas de desarrollo o desarrollo alternativo. Arturo Escobar (2013a) ha declarado que ya hay una alternativa tangible y concreta para el desarrollo, el Buen Vivir (Sumak kawsay en quichua o Sumak qamaña en aimara); concepto importante que se puede considerar como parte de esta tercera corriente de crítica al desarrollo, según Eduardo Gudynas (2017) es un paradigma que no tiene orígenes académicos, sino que deviene de prácticas sociales y políticas de una diversidad de actores (sobre todo indígenas); su ética del desarrollo subordina los objetivos económicos a criterios ecológicos, a la dignidad humana y a la justicia social (Escobar, 2013b).

Refiere Fernando Huanacuni (2010) que el desarrollo es inapropiado y altamente peligroso de aplicar en las sociedades indígenas, tal cual es concebido en el mundo occidental, porque aniquila lentamente la filosofía del Vivir Bien (como también se le conoce al Buen vivir), al desintegrar la vida comunal y cultural de las comunidades, así como devastar también las bases de subsistencia y de sus capacidades y conocimientos para la satisfacción de las propias necesidades de los pobladores (citado en Gudynas, 2011). El Buen Vivir, desde una postura holística descansa en la cosmovisión de los pueblos indígenas; contrario al desarrollo, se aleja del bienestar social que descansa en los bienes materiales como únicos determinantes; considera otros valores como: el conocimiento y reconocimiento social y cultural, códigos de conductas éticas o espirituales que tienen que ver con la sociedad y la naturaleza, valores humanos, y otros (Acosta, 2008).

El Buen Vivir representa una protesta a las formas neoliberales de entender el desarrollo, siendo aquellas que celebran el consumo material como indicadores de bienestar (Gudynas, 2011) y desmantelan tradiciones, culturas, naturaleza y medio ambiente. Refiere Acosta (2008: 6) "el Buen Vivir constituye una oportunidad para construir colectivamente un nuevo régimen de desarrollo". Este proyecto reconoce las diferencias culturales y de género, su principio rector es la interculturalidad, sostiene que la vida implica la creación de la forma, es decir la diferencia, la morfogénesis; en esta concepción, el mundo es un pluriverso (Escobar, 2013b).

Entendiendo que pluriverso se refiere a una red siempre cambiante de interrelaciones entre seres humanos y no humanos, o como es descrito por los zapatistas un 'mundo donde quepan muchos mundos'.

\section{Conclusiones}

En los apartados anteriores se hizo una revisión histórica muy práctica de lo que ha representado el modelo económico neoliberal en diferentes contextos de la historia, destacando su fracaso en la actualidad para con el mundo en general, pero constatando que lo que sí ha logrado es una acumulación de poder en ciertas élites. La panacea de un mundo con mayores oportunidades y desarrollo para todos no se cumplió, por el contrario, se ha acentuado la desigualdad, el despojo, la pobreza, y el hambre. 
El virus COVID-19 es un fenómeno a nivel global que obliga a evaluar la funcionalidad del modelo capitalista neoliberal. Quedó en evidencia que el libre mercado no puede resolver los problemas sociales, el resultado se puede observar en el colapso de los sistemas de salud, millones de trabajadores sin seguridad social, pérdida de empleos y hambre durante el confinamiento y resguardo de la pandemia. El proyecto neoliberal que apoyaba las medidas de austeridad en los gobiernos con el recorte al gasto público, la desregulación de mercados, la privatización, y la libre competencia ha ocasionado la expansión del virus en el mundo.

La salud se convirtió en un negocio. Y las consecuencias se han hecho presente. El aislamiento y reducción del consumo mundial pone en jaque a la economía global, que tendrá estragos importantes para las sociedades en su momento. Sin embargo, es también el confinamiento y con ello la reducción de la actividad humana en el espacio público lo que ha producido un efecto inmediato en el medio ambiente, disminuyendo la generación de gases contaminantes y aminorando la crisis ecológica. Se han limpiado lagos y playas, se ha generado una consciencia solidaria, hay evidencia de que especies animales merodean territorio ganado por la urbanización; por otro lado, quienes se trasladaron por las ciudades durante los días de confinamiento expresan un disfrute por la ausencia de tráfico vehicular.

El coronavirus como es conocido, ha terminado por colapsar el mundo instaurado sobre bases políticas neoliberales. El recuento es, que el decadente modelo de globalización neoliberal tiene a los ciudadanos confinados, fronteras cerradas y una restricción comercial, que afectara a aquellas naciones que basan su economía en una enorme dependencia en el suministro de bines y servicios básicos (Torres, 2020).

Es necesario considerar que los daños se siguen acumulando, pero lo que sí se puede hacer, es reflexionar sobre las consecuencias de haber mercantilizado al ser humano. Es momento hacer un balance e incluir dichas consecuencias y necesidades en la agenda política, debemos prepararnos para responder a este enorme reto global de manera pluriversal contemplando todos los escenarios reales de cada sociedad. Se requiere detener la destrucción de la naturaleza y los ecosistemas, respetar todas las cosmovisiones, a través de la justicia social.

\section{Referencias}

Acosta, A. (2008). “El Buen Vivir, una oportunidad por construir”, Ecuador Debate, (75): 33-47.

Anderson, P. (1999). "Historia y lecciones del neoliberalismo", Revista del Centro de Estudios del Trabajo, 25.

Bustelo, E. (1998). “Expansión de la ciudadanía y la construcción democrática”. En: E. Bustelo, \& A. Minujin (edits.) Todos entran. Propuesta para sociedades incluyentes, Argentina: UNICEF-Santillana.

Cajal, A. (2020). "5 causas y consecuencias del neoliberalismo”, obtenido de: Lifeder.com, https://www.lifeder.com/causas-consecuencias-neoliberalismo/\#

Calvento, M. (2007). Profundización de la Pobreza en América Latina. El caso de Argentina 1995-1999, (J. C. Martínez, Ed.), Edición electrónica gratuita.

CEPAL. (2016). "Ciencia, tecnología e innovación en la economía digital. La situación de América Latina y el Caribe”, México: Comisión Económica para América Latina y el Caribe.

CEPAL. (2020). "La agenda 2030 para el desarrollo sostenible en el nuevo contexto mundial y regional. Escenarios y proyecciones en la presente crisis", Santiago, Chile: LC/PUB.

Chomsky, N., y Polychroniou, C. J. (2017). Optimism over despais: on capitalism, empire, and social change. Chicago, IL: Haymarket Books. doi:ISBN: 978-1-60846-800-3

Corredor M., C. (2003). “El problema del desarrollo”. En D. I. Restrepo Botero (Ed.) La falacia neoliberal. Crítica y alternativas (págs. 63-84), Colombia: Universidad Nacional de Colombia. 


\section{La pandemia COVID-19: desafío al discurso de desarrollo bajo el modelo económico neoliberal}

Cueto, M. (2020). "LA Covid-19 y las epidemias del neoliberalismo", El país, https://elpais.com/ ciencia/2020-03-27/la-covid-19-y-las-epidemias-del-neoliberalismo.html

Diez, J. I., Gutiérrez, R. R., \& Pazzi, A. (2013). “¿De arriba hacia abajo o de abajo hacia arriba?”, Geopolitica(s),4(2): 199-235.

Doxrud, J. (2017). "La turbulencia económica mundial de 1973", obtenido de: Libertyk.com, http://www.libertyk.com/blog-articulos/2017/9/19/la-turbulencia-econmica-mundial-de-1973-porjan-doxrud\#

El país. (2020). "Duterte ordena disparar contra quien viole la cuarentena", obtenido de: El País, https://elpais.com/internacional/2020-04-02/duterte-ordena-disparar-contra-quien-viole-lacuarentena.html

Escobar, A. (2013a). "Postdesarrollo, modernidad y otros mundos". (M. Mandujano Estrada, Entrevistador), Revista Oxímora.

Escobar, A. (2013b). "La alternativa al modelo hegemónico de desarrollo capitalista es el concepto del Buen Vivir”. (F. Arellano Ortiz, Entrevistador) Bogotá.

Escalante G., F. (2015). Historia mínima de El neoliberalismo. México: El Colegio de México.

Espinoza P., M. (2020). “COVID-19, el virus de la era neoliberal”, obtenido de: La vorágine. Cultura Crítica/ Apocaelipsis, https://lavoragine.net/covid19-virus-era-neoliberal/

Fals B., O. (1970). Ciencia propia y colonialismo intelectual. México: Nuestro tiempo.

Foucault, M. (1968). Las palabras y las cosas. Una arqueología de las ciencias humanas. México: Siglo XXi .

Friedman, M. (1966). Capitalismo y libertad. Madrid: Rialp.

Fox, J. (2001). Chomsky and globalization. Duxford: Totem Books USA, doi:ISBN 1840426237 X

González, J. I. (2003). "No hay falacia neoliberal”. En: D. I. Restrepo Botero (Ed.), La falacia neoliberal. Crítica y alternativas (págs. 85-106), Colombia: Universidad Nacional de Colombia.

Gudynas, E. (2011). "Buen vivir: Germinando alternativas al desarrollo", América Latina en Movimiento, ALAI,(162): 1-20.

Gudynas, E. (2014). "La crítica al desarrollo y la exploración de alternativas desde el buen vivir". En: C. Von Barlowen, \& M. Rivera (Edits.) Desarrollo sostenible en una modernidad plural. Perspectivas latinoamericanas (págs. 169-179), Ecuador: ABYA YALA.

Gudynas, E. (2017). "Posdesarrollo como herramienta para el análisis crítico del desarrollo", Estudios Críticos sobre el Desarrollo,7(12): 193-210.

Harvey, D. (2003). The new imperialism. Oxford: Oxford University Press.

Harvey, D. (2006). Spaces of global capitalism. Londre-Nueva York: Verso.

Harvey, D. (2007). Breve historia del neoliberalismo. Madrid, España: Ediciones Akal.

Hirshman, A. (1958). The Strategy of Economic Development. Yale: Yale University Press.

Kay, C. (2009). "Un fracaso del neoliberalismo". Nueva Sociedad,(223): 94-112.

Morales, R. (2020). "Esta recesión tendrá mayor impacto que la crisis de 2008, alerta OMC”, obtenido de: El economista, https://www.eleconomista.com.mx/empresas/Esta-recesion-tendra-mayor-impactoque-la-crisis-de-2008-alerta-la-OMC-20200326-0057.html

Murray, N. R. (1999). Historia del pensamiento económico. Unión Editorial.

Myrdal, G. (1957). Economic Theory and Underdevelpment. London: Duckworth.

Nahón, C., Rodríguez E., C., \& Schorr, M. (2006). "El pensamiento latinoamericano en el campo del desarrollo del subdesarrollo: trayectoria, rupturas y continuidades", Crítica y teoría en el pensamiento social latinoamericano, 327-388.

Nurkse, R. (1952). "Some international aspects of the problem of economic development", American Economic Review,42(2): 571-583.

OMS. (2020a). "Coronavirus disease (COVID-2019) situation reports", World Helath Organization.

OMS. (2020b). "Brote de enfermedad por coronavirus (COVID-19)", obtenido de: Organización Mundial de la Salud, https://www.who.int/es/emergencies/diseases/novel-coronavirus-2019

OMS. (2020c). "World Health Oranization". Recuperado el 2020 de diciembre de 06, de Panel de la OMS sobre la enfermedad por coronavirus (COVID-19): https:/ / covid19.who.int/

ONU. (2018). "El mundo de hoy es más rico, pero también más desigual que nunca", obtenido de: Noticias ONU, https://news.un.org/es/story/2018/12/1447091

Orgaz, C. J. (2020). "Coronavirus: "Se perderán 195 millones de empleos en solo 3 meses" por la pandemia, el alarmante informe de la OIT (y cómo afectará a América Latina)", BBC News. 
Rosestein-Rodan, P. (1943). "Problems of industrialization of Eastern and Sourth Eastern Europe", Economic Journal (53).

Rostow, W. (1960). The stages of Economy Growth. Cambridge: Cambridge University Press.

Rubio, B. (2003). Explotados y excluidos. Los campesinos latinoamericanos en la fase agroexportadora neoliberal (Segunda edición ed.). D.F. México: Plaza y Valdés, S.A. de C.V.

Sassen, S. (2016). "At the systemic edge: expulsions", Eurepean review, 24(1): 88-194, doi:10.1017/S1062798715000472

Stedman-Jones, D. (2012). The Masters of the Universe. Hayek, Friedman, and the Bitrh of Neoliberal Politics. Princenton y Oxford: Princenton University Press.

Stewart, F. (1998). "La insuficiencia crónica del ajuste". En: E. Bustelo, y A. Minijin (Edits.), Todos entran, propuesta para las sociedades incluyentes, Buenos Aires, Argentina: UNICEF-Santillana.

Torres L., J. (2020). "De todas las opciones, eligen la peor y más cruel: esto es Europa”, obtenido de: Público, https://blogs.publico.es/juantorres/2020/03/25/de-todas-las-opciones-eligen-la-peor-y-mas-cruelesto-es-europa/

Villamizar M., E., \& Uribe A., M. (2009). "El fracaso del neoliberalismo y su modelo de desarrollo”, Revista la propiedad inmaterial (13): 119-150.

Villena O., A. (2016). "La revolución neoliberal fue un éxito rotundo. El mundo es neoliberal”, ctxt Contexto y acción. 